\title{
Measuring the 7Cs of Vaccination Readiness
}

\author{
Mattis Geiger ${ }^{1}$ (D), Franziska Rees ${ }^{1}$, Lau Lilleholt², Ana P. Santana², Ingo Zettler ${ }^{2}$, \\ Oliver Wilhelm ${ }^{1}$ Cornelia Betsch ${ }^{3}$, and Robert Böhm² \\ ${ }^{1}$ Institute of Psychology and Education, Ulm University, Germany \\ ${ }^{2}$ Department of Psychology, University of Copenhagen, Denmark \\ ${ }^{3}$ Media and Communication Science, University of Erfurt, Germany
}

\begin{abstract}
Although vaccines are among the most effective interventions used in fighting diseases, vaccination readiness varies substantially among individuals. Vaccination readiness is defined as a set of components that increase or decrease AN individual's likelihood of getting vaccinated. Building on earlier work that distinguished five components of vaccination readiness (confidence, complacency, constraints, calculation, and collective responsibility), we revised the questionnaire used to measure these components to improve its psychometric properties, specifically criterion validity. In doing so, we also developed two new components of vaccination readiness: compliance and conspiracy. Compliance is the tendency to support monitoring to control adherence to regulations; conspiracy is the tendency to endorse conspiratorial beliefs about vaccination. The newly introduced 7C scale was initially piloted in a cascade of serial cross-sectional studies and then validated with $N=681$ participants from the COVID-19 Snapshot Monitoring in Denmark. We report a bifactor measurement model, convergent validity with other questionnaires, and an explanation of $85 \%$ variance in the willingness to vaccinate against COVID-19. We also present a 7-item short version of the scale. The instrument is publicly available in several languages (www.vaccination-readiness.com), and we seek collaboration to provide translations of our instrument into other languages.
\end{abstract}

Keywords: vaccination readiness, vaccine acceptance, compliance, conspiracy, measurement instrument

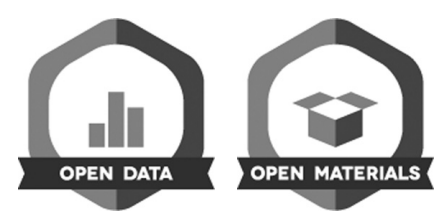

Vaccines are a breakthrough in modern medicine and are the most effective intervention against infectious diseases, such as measles or COVID-19. Of the vaccines recommended by health organizations, the benefits outweigh the risks. Nevertheless, vaccination rates are often too low to cross the critical threshold of herd immunity, which is required to eliminate a disease (Fine et al., 2011).

We assume that the vaccination rate of a population is a function of vaccination availability, that is, whether vaccines are accessible and affordable, and vaccination readiness, that is, whether citizens are ready and willing to get vaccinations. We decided to use the term vaccination readiness to introduce an overarching term that includes components that increase or decrease the likelihood of getting vaccinated. Vaccination readiness is subject to individual differences, and it varies depending on interventions aimed to increase it, such as information campaigns, public debates, and vaccine services.
To facilitate effective interventions, the components of vaccination readiness must be understood and measured using a psychometrically sound measurement tool. Earlier work identified five components of vaccination readiness: confidence, the tendency to trust in the safety and effectiveness of vaccines and to trust health authorities and experts who develop and license vaccines; complacency, the tendency to ignore vaccines because of a low perceived risk of infectious diseases; constraints, structural or psychological hurdles in daily life that make vaccination difficult or costly; calculation, the degree to which personal costs and benefits of vaccination are weighted; and collective responsibility, the tendency to consider the protection of others in the decision to vaccinate (Betsch et al., 2015, 2018).

Prior work was primarily focused on confidence (e.g., Gilkey et al., 2016; Larson et al., 2016; Sarathchandra et al., 2018), whereas the 5C (five components) scale measures all five components (Betsch et al., 2018). In several studies, the $5 \mathrm{C}$ scale yielded striking findings of the determinants of individual differences in these components and how they relate to vaccination intention and behavior. For instance, all 5C components were related to the uptake of influenza, pneumococcal, and shingles vaccines 
(Betsch et al., 2018; Nicholls et al., 2020), and all 5C components except calculation were related to the general attitude toward vaccination (Schindler et al., 2020). Furthermore, among family physicians, confidence was found to be related to vaccinating oneself and to recommending vaccines, whereas collective responsibility, constraints, and complacency were associated only with vaccinating oneself (Neufeind et al., 2020). These findings indicate that the $5 \mathrm{C}$ components predict vaccination and that the relevance of the components varies depending on the vaccine, population group, and time. Identifying the importance of different components across contexts could therefore serve to inform targeted and tailored interventions aimed at increasing vaccine uptake (WHO Regional Office for Europe, 2019).

The current COVID-19 pandemic has demonstrated that potentially, there are further components of vaccination readiness. First, conspiracy theories about vaccinations are among the most widespread and most endorsed medical conspiracy theories (Oliver \& Wood, 2014). Belief in conspiracy theories was found to lower vaccination intentions (Hornsey et al., 2018; Jolley \& Douglas, 2014). Similarly, the tendency to believe COVID-19-related conspiracy theories was negatively correlated to confidence about vaccines and the willingness to vaccinate against COVID-19 (Freeman et al., 2020; Romer \& Jamieson, 2020). Importantly, confronting people with COVID-19related conspiracy theories has been shown to causally predict lowered support for governmental regulations and adoption of protective behaviors (Pummerer et al., 2021), which makes a strong case for assuming that belief in conspiracy theories lowers vaccination readiness, too. As such, it is not sufficient to only understand people's fear of vaccinations and whether they trust them but to know whether this fear stems from conspiracy theories, that must be treated carefully in interventions.

Second, to fight the COVID-19 pandemic, many states declared a state of emergency to temporarily implement laws that restrict basic human rights, such as bans on public assembly. Citizens' acceptance of these measures varied substantially within and between countries (Vardavas et al., 2021). With available COVID-19 vaccines, states might offer benefits to vaccinated people or restrict the rights of those who refuse to vaccinate and compliance with these measures would likely vary. However, there is some evidence that a mandatory vaccination policy can cause psychological reactance, which in turn decreases vaccination intentions (Sprengholz et al., 2021). Consequently, to understand how vaccination readiness is affected by considerations about the society one lives in, asking for people's feeling of collective responsibility is one aspect, but we must also ask for individual compliance with vaccination policies.

\section{Current Research}

A psychometrically valid measurement instrument allows for a better understanding of vaccination readiness, which can then facilitate specific interventions aimed at increasing vaccination rates. This study aims to psychometrically improve the $5 \mathrm{C}$ scale of vaccination readiness and to extend it to a $7 \mathrm{C}$ (seven components) scale of vaccination readiness that also includes the components of conspiracy and compliance. To avoid an overlap between existing components and newly introduced components (e.g., the original confidence definition of the $5 \mathrm{C}$ scale included conspiracy to some degree), we redefine the components (see Table 1). In three iterative steps, we revise original items, add additional items to measure the refined 5C, develop new items to measure the two new components of conspiracy and compliance, and select the best items for the final full and short versions of the $7 \mathrm{C}$ scale. We provide them as a freely accessible tool in multiple languages.

Next, we investigate the psychometric properties of the new scale. Because of the high communality of the vaccination readiness components, we expect a bifactor confirmatory factor to fit the data well (see Figure 1). The model consists of a general factor of vaccination readiness and six specific nested factors for all components except confidence because the confidence items serve as references for the general factor. We expect high factor saturation (McDonald's $\omega$; McDonald, 2013) in the general factor and smaller but still substantial saturation in specific factors.

Second, we present a snapshot of convergent validity of the $7 \mathrm{C}$ scale, expecting differential relations among the new components. We test relations between (i) the nested conspiracy factor with COVID-19 conspiracy beliefs, (ii) the nested compliance factor with factors of political attitudes toward COVID-19 relations, and, additionally, (iii) the HEXACO personality factors honesty-humility and agreeableness with general vaccination readiness because vaccination is (partly) a prosocial decision (Betsch et al., 2013; Böhm et al., 2016, 2019).

Finally, we evaluate criterion validity by regressing COVID-19 vaccination intention on the $5 \mathrm{C}$ and $7 \mathrm{C}$ factors.

\section{Methods}

\section{Sample and Procedure}

Participants were recruited through the Danish branch of the serial cross-sectional COvid-19 Snapshot Monitoring survey (COSMO; Böhm et al., 2020). The COSMO survey runs weekly to bi-weekly to assess citizens' knowledge, perceptions, feelings, and behaviors during the COVID-19 pandemic. The survey is distributed to a random sub-sample 
Table 1. The seven components of vaccination readiness

\begin{tabular}{|c|c|c|c|}
\hline Component & Definition & Short version item & $\begin{array}{l}\text { Interpretation: High scores } \\
\text { indicate... }\end{array}$ \\
\hline \multirow[t]{2}{*}{ Confidence } & \multirow{2}{*}{$\begin{array}{l}\text { Trust in the security and } \\
\text { effectiveness of vaccinations, the } \\
\text { health authorities, and the health } \\
\text { officials who recommend and } \\
\text { develop vaccines. }\end{array}$} & $\begin{array}{l}\text { Vaccination side effects occur rarely and are not } \\
\text { severe for me. } \\
\text { Political decisions about vaccinations are } \\
\text { scientifically grounded. }\end{array}$ & \multirow[t]{2}{*}{$\begin{array}{l}\ldots \text { high trust in vaccines and go } \\
\text { along with increased vaccination } \\
\text { readiness. }\end{array}$} \\
\hline & & $\begin{array}{l}\text { I am convinced the appropriate authorities do } \\
\text { only allow effective and safe vaccines. }\end{array}$ & \\
\hline \multirow[t]{2}{*}{ Complacency } & \multirow[t]{2}{*}{$\begin{array}{l}\text { Complacency and laziness to get } \\
\text { vaccinated due to low perceived } \\
\text { risk of infectious diseases. }\end{array}$} & $\begin{array}{l}\text { I do not need vaccinations because infectious } \\
\text { diseases do not hit me hard. (R) } \\
\text { Vaccination is unnecessary for me because } \\
\text { I rarely get ill anyway. (R) }\end{array}$ & \multirow[t]{2}{*}{$\begin{array}{l}\text {... low complacency and, thus, high } \\
\text { vaccination readiness. }\end{array}$} \\
\hline & & $\begin{array}{l}\text { I get vaccinated because it is too risky to get } \\
\text { infected. }\end{array}$ & \\
\hline \multirow[t]{2}{*}{ Constraints } & \multirow[t]{2}{*}{$\begin{array}{l}\text { Structural or psychological hurdles } \\
\text { in daily life that make vaccination } \\
\text { difficult or costly. }\end{array}$} & $\begin{array}{l}\text { I make sure to receive the most important } \\
\text { vaccinations in good time. } \\
\text { Vaccinations are so important to me that } \\
\text { I prioritize getting vaccinated over other things. }\end{array}$ & \multirow[t]{2}{*}{$\begin{array}{l}\text {... everyday hurdles do not hinder } \\
\text { in getting vaccinations }\end{array}$} \\
\hline & & $\begin{array}{l}\text { I sometimes miss out on vaccinations because } \\
\text { vaccination is bothersome. }(R)\end{array}$ & \\
\hline \multirow[t]{2}{*}{ Calculation } & \multirow[t]{2}{*}{$\begin{array}{l}\text { Degree to which personal costs and } \\
\text { benefits of vaccination are } \\
\text { weighted. }\end{array}$} & $\begin{array}{l}\text { I get vaccinated when I do not see disadvantages } \\
\text { for me. }(R) \\
\text { I only get vaccinated when the benefits clearly } \\
\text { outweigh the risks. (R) }\end{array}$ & \multirow[t]{2}{*}{$\begin{array}{l}\ldots \text { cost-benefits considerations } \\
\text { about vaccinations are ignored and } \\
\text { high vaccination readiness. }\end{array}$} \\
\hline & & $\begin{array}{l}\text { For each vaccine, I carefully consider whether } \\
\text { I need it. (R) }\end{array}$ & \\
\hline \multirow[t]{2}{*}{$\begin{array}{l}\text { Collective } \\
\text { Responsibility }\end{array}$} & \multirow[t]{2}{*}{$\begin{array}{l}\text { Willingness to protect others and to } \\
\text { eliminate infectious diseases. }\end{array}$} & $\begin{array}{l}\text { I also get vaccinated because protecting } \\
\text { vulnerable risk groups is important to me. } \\
\text { I see vaccination as a collective task against the } \\
\text { spread of diseases. }\end{array}$ & \multirow[t]{2}{*}{$\begin{array}{l}\ldots \text { vaccination readiness to protect } \\
\text { others. }\end{array}$} \\
\hline & & $\begin{array}{l}\text { I also get vaccinated because I am thereby } \\
\text { protecting other people. }\end{array}$ & \\
\hline \multirow[t]{2}{*}{ Compliance } & \multirow[t]{2}{*}{$\begin{array}{l}\text { Support for societal monitoring and } \\
\text { sanctioning of people who are not } \\
\text { vaccinated. }\end{array}$} & $\begin{array}{l}\text { It should be possible to exclude people from } \\
\text { public activities (e.g., concerts) when they are not } \\
\text { vaccinated against a specific disease. } \\
\text { The health authorities should use all possible } \\
\text { means to achieve high vaccination rates. }\end{array}$ & \multirow[t]{2}{*}{$\begin{array}{l}\text {.. acceptance of punishment for } \\
\text { refusing vaccinations and } \\
\text { endorsement of benefits for } \\
\text { vaccinated people. }\end{array}$} \\
\hline & & $\begin{array}{l}\text { It should be possible to sanction people who do } \\
\text { not follow the vaccination recommendations by } \\
\text { health authorities. }\end{array}$ & \\
\hline \multirow[t]{2}{*}{ Conspiracy } & \multirow[t]{2}{*}{$\begin{array}{l}\text { Conspiracy thinking and belief in } \\
\text { fake news related to vaccination. }\end{array}$} & $\begin{array}{l}\text { Vaccinations cause diseases and allergies that } \\
\text { are more serious than the diseases they ought } \\
\text { to protect from. (R) } \\
\text { Health authorities knuckle under to the power } \\
\text { and influence of pharmaceutical companies. (R) }\end{array}$ & \multirow[t]{2}{*}{$\begin{array}{l}\ldots \text { dismissal of conspiracy beliefs } \\
\text { around vaccinations. }\end{array}$} \\
\hline & & Vaccinations contain chemicals in toxic doses. (R) & \\
\hline
\end{tabular}

Note. Confidence, collective responsibility, and compliance relate positively to vaccination readiness, and complacency, constraints, calculation, and conspiracy relate negatively to vaccination readiness. To avoid confusion, all items should be scored so that high values indicate high vaccination readiness. Items that must be reverse coded are marked with an (R). Items of the short-scale are marked in bold.

from a larger sample that is representative of the Danish adult population concerning age and gender. Participants were invited via Danish citizens' official digital mail. Data used in the current investigation were assessed in calendar week 4 in 2021 (25-31 January, 2021). Among other questionnaires not considered here, participants completed questions about political attitudes toward COVID-19 restrictions, the $5 \mathrm{C}$ scale, the $7 \mathrm{C}$ scale, questions about COVID-19 conspiracy beliefs, and the Brief HEXACO Inventory (BHI) (in this order). We provide English versions and descriptive statistics of all scales used in this study in the supplement on Open Science Framework (OSF; https://osf.io/2tg8d/). Sample size was determined by self-selection $(5,000$ participants were invited); there were no exclusion criteria except being younger than 18 years. In the sample of $N=681$ participants, $58 \%$ reported being female, $41.6 \%$ male, and 


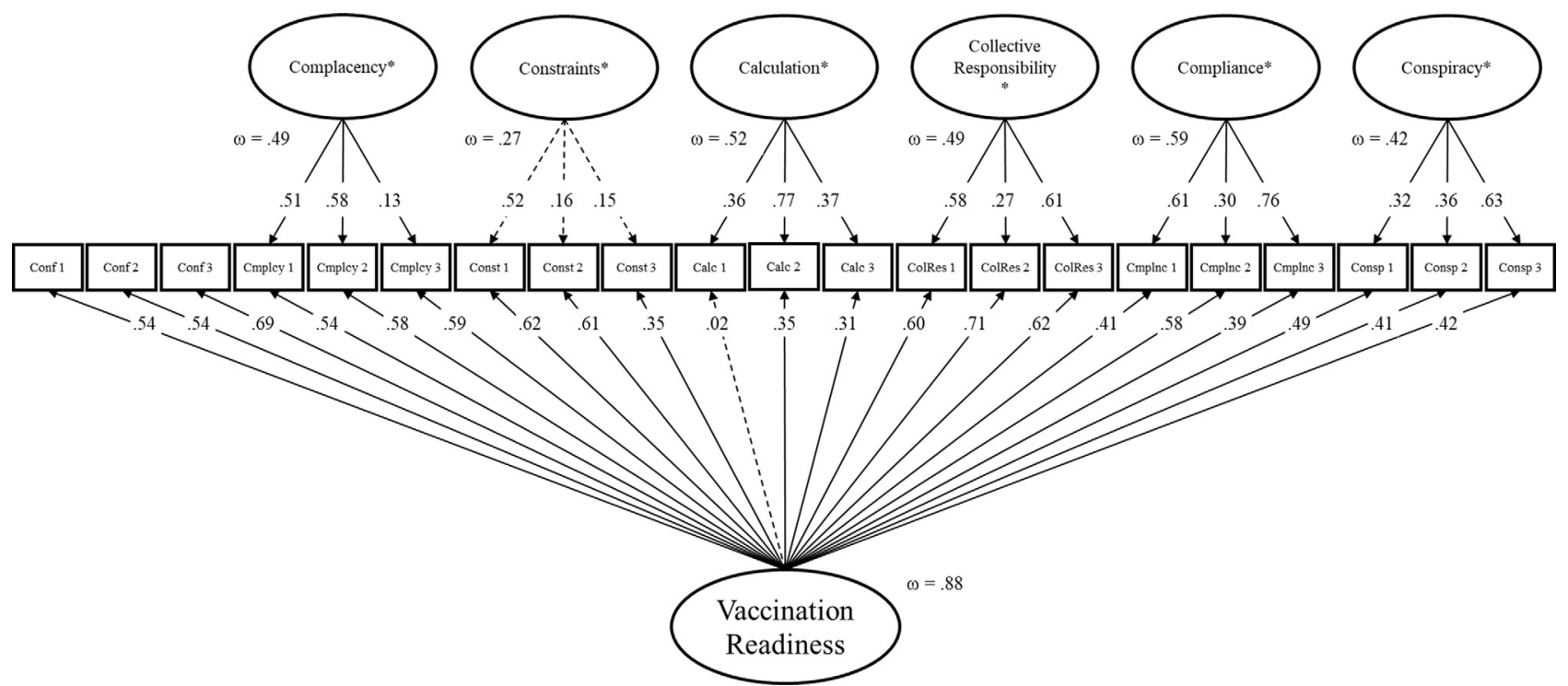

Figure 1. Confirmatory factor analysis of the $7 \mathrm{C}$ scale. Loadings are standardized, and loadings not significant on $\alpha=.05$ are depicted as dotted lines. *These factors are nested factors, so they represent what is specific to the component after controlling for general vaccination readiness. $\chi^{2}(171)=437, p<.001, \mathrm{CFI}=.927, \mathrm{TLI}=.911, \mathrm{RMSEA}=.048, \mathrm{SRMR}=.046$

$0.4 \%$ another gender. The mean age was $M=56.75$ years $(S D=15.47)$, ranging from 19 to 94 years. Eight percent of the sample had primary education, $45 \%$ had a secondary education, $46 \%$ had post-secondary education, and $1 \%$ reported "other." Compared with the adult Danish population, our sample has more females, is slightly older, and somewhat better educated. Deviations are best explained by the effects of self-selection.

\section{Materials}

\section{Vaccination Readiness Scales}

We administered the full 5C scale with three items per component (Betsch et al., 2018). An example item was: "I am completely confident that vaccines are safe" (7-point rating scale, 1 = strongly disagree to 7 = strongly agree) . The five components of vaccination readiness are highly correlated (see supplement on OSF: https://osf.io/2tg8d/) and nomologically coherent. Therefore, we model the $5 \mathrm{C}$ scale as a bifactor model (Brunner et al., 2012; Eid et al., 2008), in which all items were loaded on a general factor and four specific nested orthogonal factors for the components of complacency, constraints, calculation, and collective responsibility. Because the items of the confidence component have strong loadings on the general factor, they are used as references for the general factor.

The existing 5C scale was revised and extended to the 7C vaccination readiness scale. First, we adjusted the definitions of the components of the $5 \mathrm{C}$ scale to allow the inclusion of two new components by separating old and new components. For example, conspiracy was excluded from the $5 \mathrm{C}$ confidence definition (see the supplement on OSF: https://osf.io/2tg8d/). Existing items were revised based on four iterative criteria: (i) items with more extreme statements were formulated to reduce floor and ceiling effects found in the original scale (Betsch et al., 2018); (ii) statements were conveyed more strongly to the rater by increasing the number of first-person pronouns to increase the personal salience of items; (iii) as simple language as possible was used to enhance accessibility; and (iv) short statements were used whenever possible. Second, we revised items that were excluded during the development of the $5 \mathrm{C}$ scale, and we developed new items for the redefined five factors to allow for drawing the best items in a larger item sample. Third, we developed new items for the two new components of conspiracy and compliance. The definitions of the seven components, their interpretation, and all final 7C items are summarized in Table 1.

The 7C questionnaire was iteratively developed in three COSMO waves with samples ranging from $N=548$ to $N=949$, which adhered to the criteria described above. We used item statistics and loadings in a bifactor model to determine which items had to be revised or replaced by new items. This iterative process is provided in the supplement (https://osf.io/2tg8d/). The final 7C scale with 21 items was sampled by choosing the three highest loading items per component. We kept the original 7-point rating scale. The short and full versions are available in English in Table 1 and in several other languages at https://www.vaccination-readiness.com. 


\section{COVID-19 Conspiracy Beliefs}

COVID-19 conspiracy beliefs were assessed by five items on a 5-point rating scale developed by Pummerer and colleagues (2021). A sample item reads "The panic surrounding the novel coronavirus (COVID-19) is partially created by people trying to damage the political system." In our sample, the scale was reliable, with factor saturation $\omega=.81$.

\section{Political Attitudes Toward COVID-19-Related Restrictions}

Political attitudes toward COVID-19-related restrictions were assessed by 13 items on a 7-point rating scale developed for the COSMO survey. Five of the items stress attitudes regarding severe restrictions and strict enforcement of measures, such as "It makes sense that the authorities have the power to force people to get vaccinated against the novel coronavirus (COVID-19)," loading on a factor labeled "strong restrictions." Eight items enquired about acceptance of everyday restrictions, such as "It makes sense that the government restricts personal liberty rights to fight the novel coronavirus (COVID-19)," loading on a factor labeled "everyday life restrictions." In this study, the factors were reliable: $\omega_{\text {strong }}=.85$ and $\omega_{\text {everyday life }}=.88$.

\section{Brief HEXACO Inventory}

The personality factors honesty-humility and agreeableness were assessed by four items each on a 5-point rating scale from the Brief HEXACO Inventory (BHI; De Vries, 2013). An example of an item that assessed honesty-humility was: "I find it difficult to lie." An example of an item that assessed agreeableness was: "I often express criticism." The factor reliabilities in this study were $\omega_{\text {honest-humility }}=.44$ and $\omega_{\text {agreeableness }}=.52$.

\section{Willingness to Vaccinate Against COVID-19}

The willingness to vaccinate against COVID-19 was assessed using a single 7-point rating scale item: "If a vaccine against the novel coronavirus (COVID-19) becomes available, I would get it." Overall, the participants in this sample were very willing to vaccinate against COVID-19; hence, the response distribution was extremely negatively skewed to the right: $82.8 \%$ of the sample responded $7=$ strongly agree. To account for this extreme ceiling effect, we dichotomized the variable to $1=$ definitely willing to vaccinate (participants who responded $7=$ strongly agree) and $0=$ maybe willing or unwilling to vaccinate (participants who responded 1-6 on the rating scale). The analyses using the original variable are described in the supplement (https://osf.io/2tg8d/).

\section{Statistical Procedure}

The psychometric properties of the 7C vaccination readiness scale are investigated using a bifactor model, as shown in Figure 1. We evaluate model fit and factor saturation. Model fit is deemed acceptable at CFI and TLI $\geq .90$, RMSEA $<.08$ and SRMR $<.11$ and good at CFI and TLI $\geq .95$, RMSEA < .05 and SRMR < .08 (Bentler, 1990; Hu \& Bentler, 1999; Steiger, 1990). Correlations with covariates are modeled between the latent factors. The fit of the measurement models and the factor saturation of the covariates are reported in the supplement. In the models that predicted the dichotomous willingness to vaccinate against COVID-19, the regressions are analyzed using a logit link, and pseudo $R^{2}$ s. All models are estimated by a robust maximum likelihood estimation (MLR). Significance is evaluated on an $\alpha=.05$ threshold.

All analyses were conducted in R (version 4.0.3; R Core Team, 2020) and Mplus Version 7 (Muthén \& Muthén, 2012) using MplusAutomation Version 0.8 (Hallquist \& Wiley, 2018) in R. Factors in the confirmatory factor analyses were identified by fixing the factor variances to 1 . We provide a summary of all analyses and additional supplementary analyses, as well as the dataset we analyzed in the supplement on OSF (https://osf.io/2tg8d/).

\section{Results}

\section{Measurement Model of Vaccination Readiness}

The $7 \mathrm{C}$ scale was modeled as a bifactor model with all items loading on the general factor of vaccination readiness and six specific nested orthogonal factors of all components except confidence, which was chosen as the reference (see Figure 1). The general factor represented the general tendency to be ready and willing to vaccinate. The specific factors in this model represented variations in the components not explained by the general factor; that is, they were independent of general vaccination readiness. The model fit the data acceptably. The saturation of the general factor was large, and it ranged from insufficient to acceptable regarding specific factors.

For economical use in the field, we also compiled a 7-item short version of the 7C scale. We selected one item per component based on maximal loadings and on the highest correlations with the willingness to vaccinate. If these criteria were contradictory, we chose the item that maximized the criterion validity of the 7-item scale. In the short version, a general factor model fit the data acceptably: $\chi^{2}(14)=61, p<.001, \mathrm{CFI}=.933$, TLI $=.899$, RMSEA $=$ .070, SRMR $=.038$. The factor had good saturation at $\omega=.76$. The manifest aggregate (mean) score of the 21-item scale was correlated with the aggregate score of the 7-item short scale at $r=.92$. Therefore, both versions of the extended 7C scale had acceptable fit and saturation. 


\section{Convergent Validity Snapshot}

We found a medium-sized correlation between the nested conspiracy factor and COVID-19 conspiracy beliefs $(r=.34, p=.005)$. The general vaccination readiness factor was also related to COVID-19 conspiracy beliefs $(r=.47, p<$ .001). The nested compliance factor was highly correlated to the "strong restrictions" factor of political attitudes toward the COVID-19-related restrictions scale $(r=.60$, $p<.001)$ and weakly correlated with the "everyday life restrictions" factor $(r=.19, p<.001)$. The general vaccination readiness factor was also correlated to the COVID-19-related restriction factors (strong: $r=.44, p<$ .001 ; everyday life: $r=.63, p<.001)$. Finally, the general vaccination readiness factor was positively correlated to honesty-humility $(r=.21, p<.001)$ and agreeableness $(r=.17, p<.001)$. In summary, the 7C scale, specifically the newly introduced components of conspiracy and compliance, showed good convergent validity. A full set of convergent and divergent correlations is provided in the supplement (https://osf.io/2tg8d/).

\section{Criterion Validity of Vaccination Readiness}

To estimate the criterion validity of the $7 \mathrm{C}$ scale, we used the factors of the $7 \mathrm{C}$ bifactor model and the $5 \mathrm{C}$ factors in separate models to predict the willingness to vaccinate. The criterion validity of the $7 \mathrm{C}$ scale was high at $R^{2}=.84$ of explained variance in the criterion. The amount of variance explained by the $7 \mathrm{C}$ scale was higher than that explained by the $5 \mathrm{C}$ scale $\left(R^{2}=.77\right)$, which demonstrated that the revision and extension further improved the questionnaire. In the supplement (Table SM3.4, https://osf.io/ $2 \operatorname{tg} 8 \mathrm{~d} /$ ), we also report a stepwise regression examining the incremental predictive power of the $7 \mathrm{C}$ above the other study variables, which was large at $\Delta R^{2}=.35$. With regards to the short scales, both the 5-item and 7-item scales had the same extremely high criterion validity at $R^{2}=.78$.

\section{Discussion}

\section{Summary and Interpretation}

Because vaccination readiness is a crucial determinant of vaccination behavior, it is related to the success of vaccination programs. Hence, understanding individual differences in vaccination readiness and its components is of utmost importance. By building on and extending previous research on the $5 \mathrm{C}$ psychological antecedents of vaccination (Betsch et al., 2018), we developed the 7C scale of vaccination readiness. We provided a short, efficient, accessible, and valid tool to measure seven components of vaccination readiness: confidence, complacency, constraints, calculation, collective responsibility, conspiracy, and compliance, as well as general vaccination readiness. This new scale was psychometrically validated according to three expectations:

First, we expected that individual differences in the scale items could be successfully modeled by a theory-driven bifactor measurement model that consists of a general factor of vaccination readiness and of component-specific nested factors with confidence as reference. We found the model to fit the data acceptably. A 7-item short version was well represented by a general factor model. This model resembles the bifactor solution, but component-specificity is reflected in indicator residuals. Alternative modeling approaches, such as correlated factor models and higherorder models, are conceivable, too, because they differ only in their representation of the communality between the components. All models have advantages and disadvantages. However, the bifactor model is advantageous in studying both general and specific components.

The reliability of the general factor was good but much smaller for specific factors. This is no surprise considering the strong general factor and the nested nature of the specific factors. Nevertheless, when examining relations of the nested factors with other constructs, the limited reliability must be taken into consideration. For example, with only a little specific variance in constraints, the regression weight of this nested factor has a very large confidence interval and, thus, must be interpreted with caution. However, this does not necessarily make constraints a generally limited factor. In a Danish sample with easy access to vaccines, constraints might play less of a role than in other samples with restricted access. In other words, future research should investigate the specificity of components in different samples.

Second, we expected the newly added specific components of conspiracy and compliance to demonstrate convergent validity in differential correlations to related constructs. Convergent validities were medium to large. The general factor of vaccination readiness correlated with the convergent constructs, too, and sometimes higher than the specific factors. This, however, does not limit the convergent validity of the two new components, because in the bifactor model they carry only specific variance orthogonal to general vaccination readiness. Thus, the correlation of the specific factor with convergent variables is the incremental convergent validity of a specific factor above the convergent validity of a general factor.

Third, we expected that the $7 \mathrm{C}$ scale showed higher criterion validity in predicting the willingness to vaccinate against COVID-19 when a vaccine is available than the original $5 \mathrm{C}$ scale. We found that the 7C's predictive power was larger than that of the original $5 \mathrm{C}$ scale, indicating that 
the revisions and additional components successfully extended the construct of vaccination readiness.

However, just like the 5C scale did when it was published, the $7 \mathrm{C}$ scale reflects our current thoughts on vaccination readiness. Because of the high communality of components, not all are likely to demonstrate incremental validity (e.g., for interventions). Nevertheless, the 7C is a snapshot that reflects the state-of-the-art measurement of vaccination readiness. In the future, new components might be proposed, which will be subjected to empirical scrutiny. Furthermore, future research could use the scale to address further research questions, such as additional incremental criterion validity analysis or in how far the 7C scale is generalizable to children's vaccinations, different diseases, or cultures.

\section{Implications}

From a practical perspective, the components of vaccination readiness may be affected differently in different countries or interventions (Betsch et al., 2015). In this study, we could only present a validity snapshot of vaccination readiness, but more research is needed to further validate this construct and the 7C scale. Therefore, the regular monitoring of the $7 \mathrm{C}$ components using the newly developed scale in a nomological network of related constructs in different vaccines and population groups would assist health authorities to identify potentialities and select appropriate interventions. We also hope that additional studies will provide more representative samples to overcome current generalization limitations.

We recommend that the users of the 7C scale score all items so that high values indicate high vaccination readiness, including components with content that represents the opposite of vaccination readiness (i.e., complacency, constraints, calculation, and conspiracy). If possible, the 7C should be modeled using a confirmatory factor analysis (CFA) so that the general vaccination readiness factor, as well as the specific nested component factors, are represented. This recommendation also applies to the 7-item short version, in which the residuals of indicators could be considered to represent specific variances in the components.

If the study restrictions do not allow for latent modeling, it should be considered whether the focus is general vaccination readiness or specific components. In focusing on general vaccination readiness, the mean score of the seven items on the short version is sufficient as a manifest indicator. In focusing on specific components, we recommend using mean scores across the three items per component. However, in interpreting these scores, their communality, which is represented by the general factor in the CFA, must always be considered. This means that an intervention that effectively changes some components presumably would also affect general vaccination readiness. It will also influence the scores of other components, as they are not independent of each other.

\section{Conclusion}

Vaccination rates are crucial in fighting infectious diseases. Vaccination readiness is a fundamental individual disposition that we need to understand in promoting appropriate interventions. Measured on a population level, vaccination readiness can serve as an indicator that allows for identifying target groups and providing diagnostic support regarding interventions that could be helpful (Betsch et al, 2015). The 7C scale is publicly available in multiple languages at www.vaccination-readiness.com. We invite researchers to use the scale in searching for further determinants of vaccination readiness, developing interventions that increase vaccination readiness, providing additional translations, and introducing additional components.

\section{References}

Bentler, P. M. (1990). Comparative fit indexes in structural models. Psychological Bulletin, 107(2), 238-246.

Betsch, C., Böhm, R., \& Chapman, G. B. (2015). Using behavioral insights to increase vaccination policy effectiveness. Policy Insights from the Behavioral and Brain Sciences, 2(1), 61-73. https://doi.org/10.1177/2372732215600716

Betsch, C., Böhm, R., \& Korn, L. (2013). Inviting free-riders or appealing to prosocial behavior? Game-theoretical reflections on communicating herd immunity in vaccine advocacy. Health Psychology, 32(9), 978-985. https://doi.org/10.1037/ a0031590

Betsch, C., Schmid, P., Heinemeier, D., Korn, L., Holtmann, C., \& Böhm, R. (2018). Beyond confidence: Development of a measure assessing the $5 \mathrm{C}$ psychological antecedents of vaccination. PLoS One, 13(12), Article e0208601. https://doi.org/ 10.1371/journal.pone.0208601

Böhm, R., Betsch, C., Korn, L., \& Holtmann, C. (2016). Exploring and promoting prosocial vaccination: A cross-cultural experiment on vaccination of health care personnel. BioMed Research International, 2016, 1-9. https://doi.org/10.1155/2016/6870984

Böhm, R., Lilleholt, L., \& Zettler, I. (2020). Denmark COVID-19 Snapshot MOnitoring (COSMO Denmark): Monitoring knowledge, risk perceptions, preventive behaviours, and public trust in the current coronavirus outbreak in Denmark [Preregistration]. PsychArchives. http://dx.doi.org/10.23668/psycharchives.2795

Böhm, R., Meier, N. W., Groß, M., Korn, L., \& Betsch, C. (2019). The willingness to vaccinate increases when vaccination protects others who have low responsibility for not being vaccinated. Journal of Behavioral Medicine, 42(3), 381-391. https://doi.org/ 10.1007/s10865-018-9985-9

Brunner, M., Nagy, G., \& Wilhelm, O. (2012). A tutorial on hierarchically structured constructs. Journal of Personality, 80(4), 796-846. https://doi.org/10.1111/j.1467-6494.2011.00749.x

De Vries, R. E. (2013). The 24-item Brief HEXACO Inventory (BHI). Journal of Research in Personality, 47(6), 871-880. 
Eid, M., Nussbeck, F. W., Geiser, C., Cole, D. A., Gollwitzer, M., \& Lischetzke, T. (2008). Structural equation modeling of multitrait-multimethod data: Different models for different types of methods. Psychological Methods, 13(3), 230-253. https://doi. org/10.1037/a0013219

Fine, P., Eames, K., \& Heymann, D. L. (2011). "Herd immunity": A rough guide. Clinical Infectious Diseases, 52(7), 911-916. https://doi.org/10.1093/cid/cir007

Freeman, D., Waite, F., Rosebrock, L., Petit, A., Causier, C., East, A., Jenner, L., Teale, A.-L., Carr, L., \& Mulhall, S. (2020). Coronavirus conspiracy beliefs, mistrust, and compliance with government guidelines in England. Psychological Medicine, 1-13. https:// www.cambridge.org/core/journals/psychological-

medicine/article/coronavirus-conspiracy-beliefs-mistrust-andcompliance-with-government-guidelines-in-england/ 9D6401B1E58F146C738971C197407461

Geiger, M., Rees, F., Lilleholt, L., Santana, A. P. S., Zettler, I., Wilhelm, O., Betsch, C., \& Böhm, R. (2021). Measuring the 7Cs of vaccination readiness. [Online supplementary material]. https://doi.org/10.17605/OSF.IO/2TG8D

Gilkey, M. B., Reiter, P. L., Magnus, B. E., McRee, A.-L., Dempsey, A. F., \& Brewer, N. T. (2016). Validation of the Vaccination Confidence Scale: A brief measure to identify parents at risk for refusing adolescent vaccines. Academic Pediatrics, 16(1), 42-49. https://doi.org/10.1016/j.acap.2015.06.007

Hallquist, M. N., \& Wiley, J.F. (2018). MplusAutomation: An R package for facilitating large-scale latent variable analyses in Mplus (0.8) [R]. https://doi.org/10.1080/10705511.2017.1402334

Hornsey, M. J., Harris, E. A., \& Fielding, K. S. (2018). The psychological roots of anti-vaccination attitudes: A 24-nation investigation. Health Psychology, 37(4), 307-315. https://doi.org/ $10.1037 /$ hea0000586

Hu, L., \& Bentler, P. M. (1999). Cut-off criteria for fit indexes in covariance structure analysis: Conventional criteria versus new alternatives. Structural Equation Modeling, 6(1), 1-55. https:// doi.org/10.1080/10705519909540118

Jolley, D., \& Douglas, K. M. (2014). The effects of anti-vaccine conspiracy theories on vaccination intentions. PLoS One, 9(2), Article e89177. https://doi.org/10.1371/journal.pone.0089177

Larson, H. J., de Figueiredo, A., Xiahong, Z., Schulz, W. S., Verger, P., Johnston, I. G., Cook, A. R., \& Jones, N. S. (2016). The state of vaccine confidence 2016: Global insights through a 67country survey. EBioMedicine, 12, 295-301. https://doi.org/ 10.1016/j.ebiom.2016.08.042

McDonald, R. P. (2013). Test theory: A unified treatment. Psychology Press.

Muthén, L. K., \& Muthén, B. (2012). Mplus (Version 7) [Computer software]. Muthén \& Muthén.

Neufeind, J., Betsch, C., Habersaat, K. B., Eckardt, M., Schmid, P., \& Wichmann, O. (2020). Barriers and drivers to adult vaccination among family physicians - Insights for tailoring the immunization program in Germany. Vaccine, 38(27), 42524262. https://doi.org/10.1016/j.vaccine.2020.04.052

Nicholls, L. A. B., Gallant, A., Cogan, N., Rasmussen, S., Young, D., \& Williams, L. (2020). Older adults' vaccine hesitancy: Psychosocial factors associated with influenza, pneumococcal, and shingles vaccine uptake. PsychArchives. https://doi.org/10.31234/ osf.io/xzb8y

Oliver, J. E., \& Wood, T. (2014). Medical conspiracy theories and health behaviors in the United States. JAMA Internal Medicine, 174(5), 817-818. https://doi.org/10.1001/jamainternmed.2014.190

Pummerer, L., Böhm, R., Lilleholt, L., Winter, K., Zettler, I., \& Sassenberg, K. (2021). Conspiracy theories and their societal effects during the COVID-19 pandemic. Social Psychological and Personality Science. Advance online publication. https:// doi.org/10.1177/19485506211000217
R Core Team. (2020). R: A language and environment for statistical computing (3.5.2) [Computer software]. R Foundation for Statistical Computing. https://www.R-project.org/

Romer, D., \& Jamieson, K. H. (2020). Conspiracy theories as barriers to controlling the spread of COVID-19 in the US. Social Science \& Medicine, 263, Article 113356

Sarathchandra, D., Navin, M. C., Largent, M. A., \& McCright, A. M. (2018). A survey instrument for measuring vaccine acceptance. Preventive Medicine, 109, 1-7. https://doi.org/10.1016/j. ypmed.2018.01.006

Schindler, J., Schindler, S., \& Pfattheicher, S. (2020). The role of intuition in vaccination attitudes. Journal of Health Psychology. Advance online publication. https://doi.org/10.1177/ 1359105320925160

Sprengholz, P., Felgendreff, L., Böhm, R., \& Betsch, C. (2021) Vaccination policy reactance: Predictors, consequences, and countermeasures. PsychArchives. https://doi.org/10.31234/osf. io/98e4t

Steiger, J. H. (1990). Structural model evaluation and modification: An interval estimation approach. Multivariate Behavioral Research, 25(2), 173-180.

Vardavas, C., Odani, S., Nikitara, K., El Banhawi, H., Kyriakos, C. Taylor, L., \& Becuwe, N. (2021). Public perspective on the governmental response, communication and trust in the governmental decisions in mitigating COVID-19 early in the pandemic across the G7 countries. Preventive Medicine Reports, 21 Article 101252. https://doi.org/10.1016/j.pmedr.2020.101252

WHO Regional Office for Europe. (2019). Tailoring immunization programmes. https://apps.who.int/iris/bitstream/handle/10665/ 329448/9789289054492-eng.pdf

\section{History}

Received February 25, 2021

Revision received April 20, 2021

Accepted April 22, 2021

Published online June 16, 2021

EJPA Section/Category Miscellaneous/Other

\section{Acknowledgment}

We are grateful to an expert group of the Danish Health Authority for helpful comments on adapting the survey items, and to Cecilie F. Strandsbjerg and Josefine T. Meineche for translations.

\section{Authorship}

Mattis Geiger, Franziska Rees, Oliver Wilhelm, Robert Böhm, Cornelia Betsch, Ana P. Santana, and Ingo Zettler iteratively revised and extended the $5 \mathrm{C}$ to the $7 \mathrm{C}$ vaccination readiness scale; Lau Lilleholt, A. P. Santana, and I. Zettler commented on the final version and translated it for the study. R. Böhm, L. Lilleholt, and I. Zettler programmed the study and collected all data. F. Rees analyzed the data together with M. Geiger and O. Wilhelm. M. Geiger wrote the first draft of the manuscript; R. Böhm, O. Wilhelm, and C. Betsch added sections to the manuscript. All authors reviewed the manuscript, M. Geiger drafted the final version.

\section{Open Science}

We report how we determined our sample size, all data inclusion/ exclusion criteria, whether inclusion/exclusion criteria were established prior to data analysis, all measures in the study, and all analyses including all tested models. If we use inferential tests, we report exact $p$ values, effect sizes. 95\% confidence is reported in the supplement. Supplemental material is publicly available on the Open Science Framework: https://osf.io/2tg8d/ and on the website www.vaccination-readiness.com. 
Open Data: I confirm that there is sufficient information for an independent researcher to reproduce all of the reported results, including codebook if relevant (Geiger et al., 2021).

Open Materials: I confirm that there is sufficient information for an independent researcher to reproduce all of the reported methodology (Geiger et al., 2021).

Preregistration of Studies and Analysis Plans: This study was not preregistered.

\section{Funding}

This research was funded by grants from both the Lundbeck Foundation (R349-2020-592) and the Faculty of Social Sciences, University of Copenhagen to Robert Böhm and Ingo Zettler, and the German Research Foundation (BE3970/12-1) to Cornelia Betsch.

\section{ORCID}

Mattis Geiger

(iD https://orcid.org/0000-0001-9463-858X

\section{Mattis Geiger}

Institute of Psychology and Education

Ulm University

Albert-Einstein-Allee 47

$89081 \mathrm{Ulm}$

Germany

mattis.geiger@uni-ulm.de 